\title{
Evaluation of Antibiotics use in Orthopedic Procedures
}

\author{
Shubham Babu Gupta ${ }^{1,2}$, Pankaj Wadhwa ${ }^{1 *}$ \\ 'School of Pharmaceutical Sciences, Lovely Professional University, Punjab, INDIA. \\ ${ }^{2}$ Department of Pharmacy Practice, Malla Reddy Institute of Pharmaceutical Sciences, Telangana, INDIA.
}

\begin{abstract}
Background: Appropriate utilization of antimicrobial specialists is imperatively significant from clinical points. Present anti-microbial agents are one of very crucial for clinical consideration and assume a significant job profile, both in prophylaxis and treatment of irresistible illnesses. Not with standing, their abuse is an overall issue with the degree of the issue being more prominent in the developing nations. Objective: To observe the utilization of antimicrobials for prophylaxis and treatment among patients who have faced orthopedic medical procedure. Methodology: An imminent and observational examination was led on 130 clinical records of orthopedic patients who experienced medical procedure. Result: We have selected the data of 130 patients, comprises of 70 male and 60 female patients who underwent the orthopedic medical surgeries. It was observed that the most commonly used antimicrobials classes were cephalosporin's (76.43\%) and cefuroxime $(67.40 \%)$, for prophylaxis and treatment, respectively. It was find out that almost half of cases for prophylaxis were inappropriate whereas around $73.07 \%$ of antibiotics treatment neglected to hold fast
\end{abstract}

to guidelines. Conclusion: Generally, this investigation includes the maximum numbers of patients from open reduction internal fixation (ORIF) and total hip replacement surgeries, respectively. The results of study observed the some degree of inappropriateness to some extent in case of surgical prophylaxis during orthopedic procedures.

Key words: Antibiotics, Surgery, Prophylaxis, Investigation, Inappropriateness, ORIF.

\section{Correspondence}

\section{Dr. Pankaj Wadhwa,}

School of Pharmaceutical Sciences, Lovely Professional University, Phagwara (Punjab)-144401, INDIA.

Phone: +917014825117

Email: pankaj.23400@1pu.co.in

DOI: $10.5530 /$ jyp.2020.12s.55

\section{INTRODUCTION}

Antimicrobial operators are one of the significant segments according to clinical thought and assume a critical job in both prophylaxis and treatment, separately. The reports recommend that different things, for example, their availability, assurance and authentic use are significant focuses to be thought of. In many developing nations, the issues identified with abuse of antimicrobial's without specialist's solution are driving reason for against microbial resistance. ${ }^{1}$ Prophylactic antimicrobials are comprehensively used in medical procedures and record for liberal enemy of contamination use in various crisis facilities. The inspiration driving Surgical antimicrobial prophylaxis (SAP) is to diminish the irrational use of anti-infection agents in post-surgical infections at or close around the cautious site. By preventing surgical site infections (SSI), prophylactic antimicrobial administrators can decrease hospitalization costs for certain medical procedures that speak to vital inconveniences of Surgical Site Infection (SSI). In this manner, the boorish or capricious use of prophylactic antimicrobial can reduce the incidence of antibiotic resistance. ${ }^{2}$ They affect patient's mortality and morbidity and contribute significantly to economic burden. The use of preoperative anti-microbial agents by adhering to the antimicrobial guidelines is required to reduce both the post-operative infections and emergence of antibiotic resistance. ${ }^{3}$ The timing, dose and duration of the antimicrobial prophylaxis plays a major role in combatting the antibiotic resistance as its believed to be given approximately $1 \mathrm{hr}$ before surgery to have maximum effect and therapeutic action. ${ }^{4}$ Previous investigations have been shown that antibiotics must act dynamically against major foreseen pathogens and more likely than not arrived at adequate focus in the tissue or body liquids in danger when of bacterial difficulties. The requirement for proceeding with anti-microbial prophylaxis of activity, nonetheless, has been unsure. ${ }^{5}$ Earlier similar studies have done all over world which concluded that there is a high extent of inappropriate antimicrobials use for patients who conceded at surgery ward and these investigations have moreover proposed purposes behind impropriety as an over the top term of treatment, mistaken planning of organization, deficient antibacterial range of the medications utilized and pointless blend of two anti-infection agents. $^{6-9}$ This issue is advanced to some extent by inappropriate anti-infection agents recommending is conduct and use. Therapeutically wrong, inadequate and monetarily unnecessary utilization of antibiotics is a typical medicinal services framework issue all through the world particularly in the creating comities. ${ }^{10-16}$ This examination planned for distinguishing unseemly utilization of medications specially antibiotics for prophylaxis and therapy at surgical ward which fills in as a benchmark information for wellbeing authority and policymaker and it helps in creating systems which regulates the overuse of medicaments and also helps in reducing the economic burden at the clinic level by just following the guidelines during emergency clinic administration. ${ }^{17-19}$

\section{MATERIALS AND METHODS}

Study site: It is conducted in Tertiary care Hospital specifically in orthopedic ward as the study involves patient's undergone orthopedic surgical procedures.

Study Duration: The study was performed during the period of September 2019 to December 2019.

Study design: It is a prospective and observational study where the sample selection is done by randomization subjects medical records is been analyzed to extract the information. 


\section{Eligibility criteria}

Inclusion criteria: The study includes the randomly selected clean and contaminated surgeries Patients undergoing orthopedic surgery, patients of all ages and either gender.

Exclusion criteria: Patients with confirmed microbiological testing indicative of infections diabetic patients, minor incisions and pregnancy cases were not considered in this section.

Sample size: The sample size was selected by using the given formula.

$$
\mathrm{N}=\mathrm{Z} 2 \mathrm{P}(1-\mathrm{P}) \mathrm{D}^{2}
$$

Where: $\mathrm{N}$ represents the sample size required; $\mathrm{P}$ is for Prevalence rate of antibiotics; $\mathrm{Z}$ stands here for the standard normal confidence at interval of $95 \%$ and it equals to value of 1.96. At last the D describes the margin of sampling error tolerated.

Sampling technique: Here, stratified random sampling method was employed as appropriated method to finally get relevant sample. ${ }^{20-21}$

Study variables: In present study two types of variables are considered viz rationality of antibiotic surgical prophylaxis as a dependent variable and other factors such as age of the patients, gender and type of surgery, geographical area, antibiotics used and duration of hospital stay as the part of Independent variable, respectively.

Data Collection Tool: A well-defined Performa is designed to get the relevant information desired for study.

Data quality control: To expand precision of this investigation, information assortment position was approved with its objective and grew adequate to achieve the goal of the assessment. This information assortment position was pre-tried on almost $5 \%$ of patient's cards from a similar source populace before beginning genuine information assortment and that were also not considered in the present study. Furthermore, ordinary test for fulfillment and steadiness of the information was maintained regularly. The consistency and validation of gathered information was done by using two fold technique of SPSS ${ }^{\oplus}$ software ${ }^{[22-23]}$.

Data analysis and presentation: Information section and investigation was completed utilizing factual bundle for sociology (SPSS) rendition 20.0. Engaging measurements were utilized for factual examination. The outcome was broke down and exhibited utilizing tables and diagrams. Information accessible was deciphered and talked about with the after effects of comparative investigations. ${ }^{24-25}$

Ethical consideration: A request letter was duly signed from our institute that is Lovely Professional University, Punjab, India and the same has been sent to hospital where we have planned to conduct the study. After prior approval from ethical committee of respected organization to seek permission for conduction of study, the work has been carried out.

\section{RESULT AND DISCUSSION}

The study was conducted by considering several parameters. The obtained results are represented in tabular form focusing on each individual parameter. The detailed discussion was carried out in next section. The obtained results are as such following:

\section{Socio- demographic characteristics}

A total of 130 patients who has undergone orthopedic procedure are analyzed. The numbers of patients were categorized into four age groups such as between 30-40 years (contributed almost 38.46\%), 41-50 years (almost 19.23\%), 51-60 years (almost 29.23\%) and last was those who have age more than 60 years. It was found that irrationality of the antibiotics were high in 51-60 years of age that is prophylaxis $(39.47 \%)$ and then for treatment (57.89\%), as the complete data is shown in Table 1.

\section{Therapeutic Indication}

In present study, various types of surgical procedure such as ORIF, total hip replacement, wound debriment, arthroplasty, implants, closed reduction-internal fixation (CRIF), total knee replacement surgery (TKR) and skin grafting, respectively. It was also found that among all most cases were belongs to only open reduction and internal fixation (ORIF) (43.07\%) followed by total hip replacement (20\%), as represented in Table 2

\section{No. of antibiotics prescribed for prophylaxis and treatment}

During the study, it was found that cefuroxime, which is a member of $2^{\text {nd }}$ generation cephalosporin family was most commonly prescribed antibiotic. The data suggested that almost its 67.40 and $58.17 \%$ followed by amikacin $14.91 \%$ and 14.90 for prophylaxis and treatment consumptions were observed, respectively. The detailed data is represented in Table 3.

\section{Antibiotic regimen (Single/ Multiple)}

The total number of patients treated with single regimen for prophylaxis and treatment were $76(58.91 \%)$ and $13(9.15 \%)$, respectively. It was also found that treatment regimen had very less percentage of single regimens as compared to prophylaxis. Almost 95 patients (66.90\%) have received the two- drug regimen in case of treatments. At the time of three drugs regimen in both cases it around $15 \%$. But for four drugs therapy, it was observed to be $4(3.10 \%)$ and $14(9.85 \%)$, respectively, as represented in Figure 1.

\begin{tabular}{|c|c|c|c|c|}
\hline \multirow[t]{3}{*}{ S.No } & \multirow{3}{*}{$\begin{array}{c}\text { Socio- } \\
\text { demographic } \\
\text { characteristics }\end{array}$} & \multirow{3}{*}{$\begin{array}{c}\text { Frequency } \\
\text { N (\%) }\end{array}$} & \multicolumn{2}{|c|}{ Inappropriateness of antibiotic used } \\
\hline & & & For & For \\
\hline & & & Prophylaxis N (\%) & Treatment N (\%) \\
\hline \multirow{6}{*}{1} & \multicolumn{4}{|c|}{ Age group (year) } \\
\hline & $30-40$ & $50(38.46)$ & $25(38.46)$ & $39(41.05)$ \\
\hline & $41-50$ & $25(19.23)$ & $19(29.23)$ & $24(25.26)$ \\
\hline & $51-60$ & $38(29.23)$ & $15(23.07)$ & $22(23.15)$ \\
\hline & $>60$ & $17(13.07)$ & $06(9.23)$ & $10(10.52)$ \\
\hline & Total & $130(100)$ & $65(100)$ & $95(100)$ \\
\hline \multirow{3}{*}{2} & \multicolumn{4}{|c|}{ Sex } \\
\hline & Male & $70(53.84)$ & $42(64.61)$ & $55(57.89)$ \\
\hline & Female & $60(46.15)$ & $23(35.38)$ & $40(42.10)$ \\
\hline
\end{tabular}

$\mathrm{N}$ - is the number of patient

Table 2: Diagnosis of orthopedic patients who underwent surgery at Tertiary care hospital from September 2019 to December 2019.

\begin{tabular}{ccc}
\hline Diagnosis & Frequency & Percentage (\%) \\
\hline ORIF & 56 & 43.07 \\
Total Hip Replacement & 26 & 20 \\
Wound Debriment & 13 & 10 \\
Arthroplasty & 10 & 7.69 \\
Implants & 09 & 6.92 \\
CRIF & 10 & 7.69 \\
TKR & 04 & 3.07 \\
Skin grafting & 02 & 1.53 \\
Total & 130 & 100 \\
\hline
\end{tabular}




\section{Appropriateness of antibiotics}

Appropriateness of antibiotics used for prophylaxis was found to be around $50 \%$. But in case of treatment, adherences to standard guidelines were relatively very less and it was around $27 \%$, as data has been shown in Table 4. We have also tried to represent appropriateness of antibiotics diagrammatically in Figure 2.

\section{Single regimen}

As indicated in Table 5, the drug ceftriaxone was found to be the most commonly prescribed antibiotic. According to our results, it accounts for almost 98.75 and $96.5 \%$ in favor of prophylaxis and treatments, respectively.

\section{Combination regimen}

Various types antibiotics combination regimen were used for prophylaxis such as Ceftriaxone+ Amikacin+ Cefuroxime (20.68\%), Metronidazole + Ampicillin+ Cefuroxime (17.24\%), Ceftazidine + Amikacin (17.24\%),

Table 3: Representation of Total antibiotics used for surgical prophylaxis and treatment.

\begin{tabular}{ccc}
\hline Drug name & Prophylaxis & Treatment \\
\cline { 2 - 3 } & $\begin{array}{c}\text { No of patients } \\
\mathbf{N}(\%)\end{array}$ & $\begin{array}{c}\text { No of patients } \\
\mathbf{N}(\%)\end{array}$ \\
\hline Cefuroxime & $122(67.40)$ & $121(58.17)$ \\
Amikacin & $27(14.91)$ & $31(14.90)$ \\
Metronidazole & $10(5.52)$ & $14(6.73)$ \\
Amoxicillin potassium clavulanate & $04(2.20)$ & $04(1.92)$ \\
Ceftriaxone & $05(2.76)$ & $02(0.96)$ \\
Cefoperazone salbactum & $03(1.65)$ & $02(0.96)$ \\
Cefuroxime/ clavulanic acid & $02(1.10)$ & $28(13.46)$ \\
Levofloxacin & $02(1.10)$ & $01(0.48)$ \\
Linezolid & $02(1.10)$ & $03(1.44)$ \\
Cefotaxime & $01(0.55)$ & $00(00)$ \\
Total & $178(100 \%)$ & $206(100 \%)$ \\
\hline
\end{tabular}

Table 4: Representation of appropriateness of antibiotic in orthopaedic surgery at tertiary care hospital.

\begin{tabular}{|c|c|c|c|c|}
\hline Reason for & Appropriateness & Frequency & \multicolumn{2}{|c|}{ Percentage (\%) } \\
\hline \multirow{4}{*}{ Prophylaxis } & Appropriate & 65 & \multicolumn{2}{|c|}{50.00} \\
\hline & Inappropriate & $\begin{array}{l}\text { Inappropriate } \\
\text { choice }\end{array}$ & 32 & 24.61 \\
\hline & & $\begin{array}{l}\text { unnecessary } \\
\text { combination }\end{array}$ & 33 & 25.38 \\
\hline & & Total & 65 & 50.00 \\
\hline \multirow{6}{*}{ Treatment } & Appropriate & 35 & \multicolumn{2}{|c|}{26.92} \\
\hline & Inappropriate & $\begin{array}{l}\text { Excessive } \\
\text { duration }\end{array}$ & 40 & 30.76 \\
\hline & & Short duration & 03 & 2.30 \\
\hline & & $\begin{array}{l}\text { Inappropriate } \\
\text { choice }\end{array}$ & 09 & 6.92 \\
\hline & & $\begin{array}{l}\text { unnecessary } \\
\text { combination }\end{array}$ & 43 & 33.07 \\
\hline & & Total & 95 & 73.07 \\
\hline
\end{tabular}

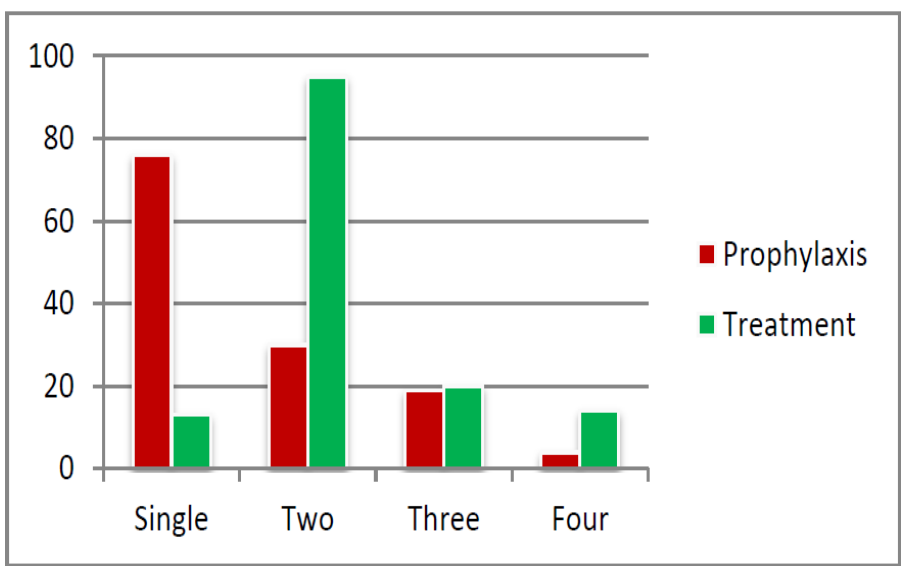

Figure 1: Showing the antibiotic regimen used for prophylaxis and treatment in orthopedic procedures.

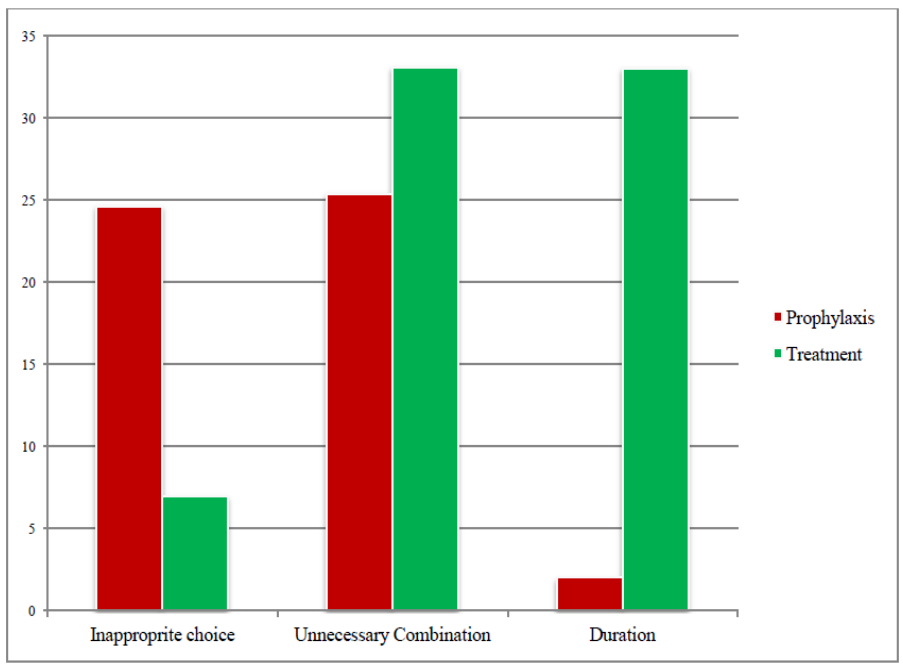

Figure 2: Showing inappropriate antibiotic prescribed for prophylaxis and treatment in orthopaedic procedures

Table 5: Antibiotics regimen (single) prescribed for patients at Tertiary care Hospitals September 2019 to December 2019.

\begin{tabular}{cccc}
\hline Antibiotic used & $\begin{array}{c}\text { Prophylaxis No of } \\
\text { patients N (\%) }\end{array}$ & $\begin{array}{c}\text { Treatment No of } \\
\text { patients N (\%) }\end{array}$ & Total N (\%) \\
\hline Ceftriaxone & $158(98.75 \%)$ & $83(96.5 \%)$ & $241(97.97)$ \\
Ampicillin & $2(1.25 \%)$ & - & $2(0.81)$ \\
Norflaxacillin & - & $3(3.5 \%)$ & $3(1.22)$ \\
Total & $160(100 \%)$ & $86(100 \%)$ & $246(100)$ \\
\hline
\end{tabular}

Flouroquinoloes + Amikacin (17.24\%), For treatment; Ceftrixone + Cefuroxime (34.04\%), Ceftrixone + Metronidazole+ Amikacin (23.40\%), Levofloxacin + Metronidazole+ Amikacin (6.38\%), respectively. The detailed related data is shown in Table 6.

\section{Antibiotic Class prescribed}

There are large numbers of antibiotics are available in the market. Our results showed that in both prophylaxis and treatments cases, maximum times only cephalosporin's (more then 76\%) and Penicillin's (more then 15.51\%) were prescribed, as shown in Table 7. 
Table 6: Antibiotic combination regimen used for prophylaxis and treatment.

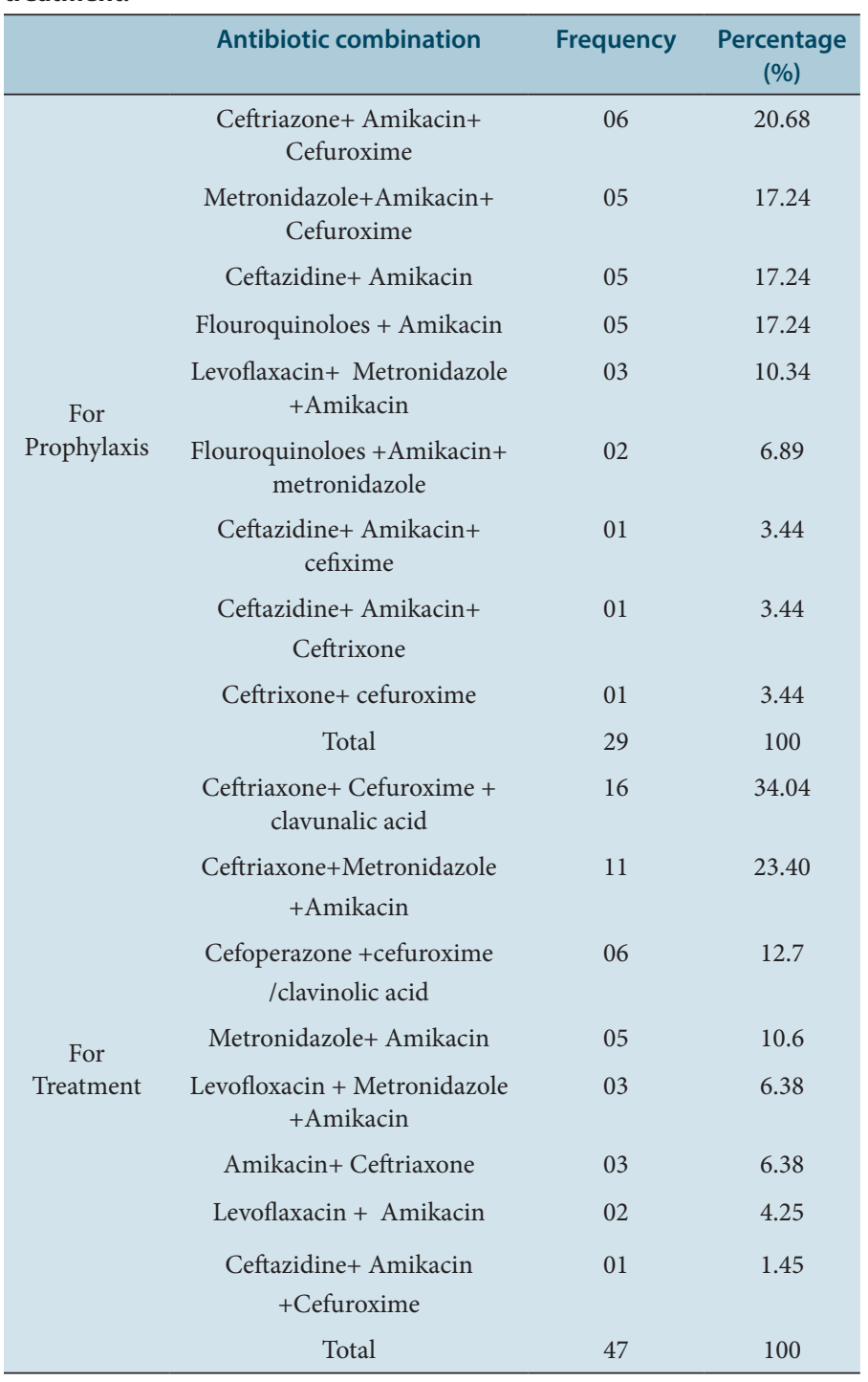

Table 7: Commonly prescribed antibiotic regimen orthopaedic surgery.

\begin{tabular}{cccc}
\hline Class of antibiotic & $\begin{array}{c}\text { For prophylaxis } \\
\text { N (\%) }\end{array}$ & $\begin{array}{c}\text { For treatment } \\
\text { N (\%) }\end{array}$ & Total (\%) \\
\hline Cephalosporin's & $133(76.43)$ & $157(76.21)$ & $290(76.31)$ \\
Penicillin's & $27(15.51)$ & $31(15.04)$ & $58(15.26)$ \\
Nitro imidazole & $10(5.74)$ & $14(6.79)$ & $24(6.31)$ \\
Oxazolidinone antibiotic & $02(1.14)$ & $03(1.45)$ & $05(1.31)$ \\
Fluoroquinolones & $02(1.14)$ & $01(0.48)$ & $03(0.78)$ \\
Total & $174(100)$ & $206(100)$ & $380(100)$ \\
\hline
\end{tabular}

\section{CONCLUSION}

The present studies have indicated the most of the patients who underwent surgical procedures in the orthopedics section received SAP. In mostly cases, the predominance of ORIF (around $43.07 \%$ ) followed by total hip substitution were observed. On the other hand, the practice was not associated with standard guidelines due to some issues with inappropriate drug selection and duration of administration was observed in some cases. Prospective and observational examination is one of major reason as the limitation of this assessment. It is slightly hard to assess how the patients took their medicine and to observe any unfortunate effect of the medicines. Being anticipated assessment additionally made us not to examine significant factors including training level, adherence and calm prosperity pro correspondence and provider and prosperity structure related factors.

\section{ACKNOWLEDGEMENT}

I sincerely thank and extend my deep sense of gratitude to the tertiary care hospital and all the healthcare providers who helped me and guided me throughout my research work.

\section{CONFLICT OF INTEREST}

The authors declare no Conflict of interest.

\section{ABBREVIATIONS USED}

ORIF: Open reduction internal fixation; SAP: Surgical antimicrobial prophylaxis; SSI: Surgical site infections; CRIF: Closed reduction internal fixation; TKR: Total knee replacement.

\section{REFERENCES}

1. Imranuddin M, Asfin M, Sruthi V, Deshpande S, Reddy MVR, et al. (2015) Cost analysis and prescribing patterns of antibiotics in postoperative surgery patients. Indo Am j pharm 5: 2231-6876.

2. Alavi SM, Roozbeh F, Behmanesh F, Alavi L (2014) Antibiotics use patterns for surgical prophylaxis site infection in different surgical wards of a teaching hospital in Ahvaz, Iran. Jundishapur J Microbiol 7: e12251.

3. Willems L, Simoen S, Laekeman G (2005) Follow up of antibiotic prophylaxis impact on compliance with guidelines and financial outcomes $\mathrm{J}$ Hosp infect 60: 333-922.

4. Hoonk S, Hay J, Yook Y (2009) The efficacy of postoperative prophylactic antibiotics in orthognathic- surgery. Yonsei Med J 50: 55-59.

5. Stone HH, Haney BB, Zaura D, Eard K, Geheber E, et al. (1979) Prophylactic and preventive antibiotic Therapy, timing, duration and economics. Ann Surg 199: 691-698

6. Dinesh R, Moulya MV, Siddiq A, Bharathi DR (2015) Evaluation of antibiotic usage as surgical prophylaxis in post-operative wards. Amer Jou of Pharm Tech Res 5: 435-443.

7. Anguzu JR, Olila D (2007) Drug sensitivity pattern of bacterial isolates from septic post-operative wound on a regional referral hospital Uganda. Afr Health Sci 8: 148-154.

8. Martelli A, Mattioli FA (2000) Retrospective study showing the misuse of prophylactic antibiotics in patients undergoing appendectomy and cholecystectomy. Current Thera Res 61: 534-539.

9. Sekimuto M, Immaka Y, Evans E, Ishizaki T, Fukui T (2004) Practice variation in preoperative antibiotic use in japan. Intern Jou for Quality in Health Care 16 367-373.

10. Mohagheghi MA, Mosavi A, Khatemi M (2005) Community based out the patent practice of antibiotics use in Tehran. Pharm Epid Drug Saf 14: 135-138.

11. Yang SF, Nadimi S, Eggerstedt M, Thorpe E, Pittman A (2016) Antibiotic prophylaxis and postoperative wound infection rates in salvage surgery for head and neck cancer. Head Neck Cancer Res 1: 1-5.

12. Kumar NS, Varaprasad CP, Thyag A, Sudarsanan S, Reddy YH (2016) Prescribing pattern of antibiotics in surgical department in a tertiary care teaching hospital. World Jour of Pharma Res 5: 1138-1147.

13. Radji M, Aini F, Fauziyah S (2014) Evaluation of antibiotic prophylaxis administration at the orthopedic surgery clinic of a tertiary hospital in Jakarta. Indonesia Asian Pac J Trop Dis 4: 190-193.

14. Rajeshwari, Nagabushan H (2016) Drug utilization study in postoperative patients in obstetrics and gynecology ward of tertiary care hospital. Int J Basic Clin Pharmacol 5: 329-334.

15. Achong MR, Houser BA, Krusky JL (1977) Rational and irrational use of antibiotics in a Canadian teaching hospital. Can med Assoc J 116: 256-259.

16. Chaudhary K, Panka J, Atul J, Arvind MK, Gaurav, et al. (2015) Usage of antimicrobials in post-operative patients in a tertiary care teaching rural hospital in India 2: 328-337.

17. Food, Medicine and Healthcare Administration and Control Authority of Ethiopia Standard Treatment Guidelines for General Hospital (3rd eds.) Ethiopia 2014: 13-20

18. Testa M, Stillo M, Giacomelli S, Scofonne S, Zotti CM (2015) appropriate use of antimicrobial prophylaxis: un observation study in 21 surgical wards of Public 
hospital 15: 63.

19. Roy BC, Hanifa A, Alam S, Naher S, Sarkar P (2015) Etiological spectrum of obstructive jaundice in tertiary care. Global Jou of Med Res 4: 1-5.

20. Baktygul K, Marat B, Ashirali Z, Rashid H, Sakamoto J (2011) An assessment of antibiotics prescribed at the secondary health-care level in the Kyrgyz republic 73: $157-168$

21. Soressa U, Mamo A, Hiko D, Prevalence FN (2016) Causes and management outcome of intestinal obstruction in Adama Hospital, Ethiopia. BMC Surgery 16: $1-8$.
22. Argaw NA, Shumbash KZ, Asfaw AA, Hawaze S (2017) Assessment of surgical antimicrobial prophylaxis in orthopedics and traumatology surgical unit of a tertiary care teaching hospital in Addis Ababa. BMC Res Notes 10: 2-8.

23. Giri BR, Pant HP, Shankar PR, Sreeramareddy CT, Sen PK (2008) Surgical site infection and antibiotics use pattern in a tertiary care hospital in Nepal. JPMA 58: 148-151.

24. Hogerzeil HV (1995) Promoting rational prescribing: an international perspective. Br J Clin Pharmac 39: 1-6.

25. Fonseca LG, Conterno L (2004) Audit of antibiotic use in a Brazilian University Hospital. Braz J Infect Dis 8: 272-280.

Article History: Submission Date : 09-03-2020; Revised Date : 28-04-2020; Acceptance Date : 16-05-2020.

Cite this article: Kotha Y, Kandhula AG, Janapareddi K. Development and Characterisation of Levodopa Loaded Pharmacosomes for Brain Targeting via Intranasal Route: Pharmacodynamic Evaluation in Rats. J Young Pharm. 2020;12(2)Suppl:s97-s101. 